\title{
ENT updates
}

\section{Pediatric Tracheotomies: A 5-Year Experience In 152 Children}

\author{
Fatih Alper Akcan'1, Yusuf Dündar², Ahmet Uluat ${ }^{3}$, \\ Derya Cebeci1 ${ }^{1}$, Mehmet Ali Sungur $^{4}$, Nergis Salman $^{5}$, İlhan Ünlü ${ }^{1}$ \\ ${ }^{1}$ Dïzce University School of Medicine, Department of Otorbinolaryngology, Dïzce, Turkey \\ ${ }^{2}$ Wayne State University Department of Otolaryngology - Head \& Neck Surgery, Detroit/MI, USA \\ ${ }^{3}$ Ministry of Health, Evliya Çelebi Training and Research Hospital, Department of Otolaryngology, Kutahya, Turkey \\ ${ }^{4}$ Dizzce University School of Medicine, Department of Biostatistic, Dïzce, Turkey \\ ${ }^{5}$ Ankara Children's Hematology and Oncology Research and Training Hospital, Department of Otorbinolaryngology, Ankara, Turkey
}

\begin{abstract}
Objective: To analyze the indications, complications, and outcomes of pediatric tracheotomies.

Material and methods: All tracheotomies performed in a tertiary referral center between January 2011 and December 2015 were reviewed retrospectively. Demographic characteristics of patients, types of referral to hospital, tracheotomy indications, preoperative evaluation findings, surgical technique, postoperative care and complications, discharge and follow-up results were analyzed.
\end{abstract}

Results: A total of 152 pediatric patients underwent tracheotomy at our hospital during this five year period. The median age of patients at the time of tracheotomy was 15.8 months, ranging from 24 days to 17 years. Of the 152 patients, 91 had neurological diseases, 38 had cardiopulmonary diseases, 14 had craniofacial abnormalities, seven had upper airway obstruction, and two underwent tracheostomy for trauma. Eleven (7.2\%) patients experienced early complications, and $15(9.8 \%)$ experienced late complications. Twenty (13.1\%) patients were decannulated during the follow-up period. Unfortunately, 9 patients (5.9\%) died of primary disease and 3 patients (1.9\%) died of tracheostomy-related complications

Conclusions: The majority of procedures were performed for diseases leading to prolonged mechanical ventilator support such as neurological and cardiopulmonary diseases. This study demostrates the importance of tracheotomy indications, which are the main predictors of decannulation rates. The other significant predictor is pulmonary complications that may cause permanent dependence of mechanical ventilator support as a result of pulmonary failure.

Key Words: Pediatric tracheotomy, tracheostomy, decannulation, complication.

\section{Introduction}

Tracheotomy/tracheostomy is defined as the temporary or permanent opening of the trachea by a surgical procedure. Although the history of tracheotomy dates back to ancient Greece, pediatric tracheotomy is a newer procedure and was first applied by Caron in $1766^{[1]}$. Modern pediatric tracheotomy applications have been described by Trousseau since the $1800 \mathrm{~s}^{[2]}$. In 1921, a significant reduction in tracheotomy-related mortality and morbidity was observed after Jackson's redefinition of the proper technique and postoperative care recommendations ${ }^{[3]}$. Up to the 1980 s, the most common cause of tracheotomy was acute upper respiratory tract obstruction due to $\mathrm{H}$. influenza and $\mathrm{C}$. diphtheria infections, with a marked shift in the indications for tracheotomy with the onset of vaccination against these microorganisms ${ }^{[4,5]}$. Although the number of indications for tracheotomy and incidence of urgent tracheotomy are
Correspondence: Fatih Alper AKCAN, MD

Düzce University School of Medicine, Department of Otorhinolaryngology, Duzce / TURKEY e-mail: f.akcan@yahoo.com

Received: April 24, 2018; Accepted: June 24, 2018
Online available at:

www.entupdates.org DOI: 10.32448/entupdates.458961 
gradually decreasing, the number of total tracheotomies is increasing. The most important contributor to the increased overall incidence of pediatric tracheotomies is better survival outcomes in patients with mechanical ventilation support as result of improved pediatric intensive care units (PICU).

The purposes of tracheotomy in adults and in children are the following: to provide airway patency by bypassing an obstructed airway segment, to provide long-term mechanical ventilation support if needed, to facilitate patient care by clearing tracheobronchial secretions and occlusions, to prevent the development of tracheal stenosis, and to facilitate weaning from mechanical ventilation by reducing the dead space ${ }^{[6,7]}$. Today, the most common causes of tracheotomy indications are neurological disorders, cardiopulmonary diseases, craniofacial malformations, metabolic diseases and abnormal airways that require long-term mechanical ventilation support ${ }^{[8,9]}$. These changes in indications led to marked changes in postoperative care and decannulation rates. Mechanical ventilator support is required in most cases of tracheotomy, especially those caused by neurological and cardiopulmonary diseases. Unfortunately, these situations make decannulation impossible in such patients.

We aimed to analyse indications, complications and decannulation rates of pediatric tracheotomy in the current study.

\section{Materials and methods}

This study was conducted in Ankara Children's Hematology and Oncology Research and Training Hospital, one of the largest children's hospitals in Turkey after obtaining a local ethics committee approval (2013/064). All tracheotomies performed at Ankara Children's Hematology and Oncology Research and Training Hospital between January 2011 and December 2015 were reviewed retrospectively. Demographic characteristics of patients, types of referral to hospital, tracheotomy indications, findings of preoperative evaluation, surgical technique, postoperative care and complications, discharge and follow-up results were analyzed. The complications experienced within the first week were considered early complications and those afterwards were defined as late complications. All cases with sufficient data were included in the study.

Statistical analysis was performed using SPSS version 21 (IBM, Armonk, NY). Descriptive statistics were performed by independent t-tests and the Mann-Whiney U-test for mean comparisons of variables with two groupings. For variables with groupings of three or more a one-way ANOVA (analysis of variance) test was utilized. Chi-squared and Fisher's exact tests were used to analyze categorical variables. All variables were reported with percentage, median (age) and standard deviation; results were considered significant for p:0.05.

\section{Results}

\subsection{Demographics}

A total of 152 pediatric patients underwent tracheotomy at our hospital during this five year period. Of these patients, $102(67 \%)$ were male and $50(33 \%)$ were female. The median age of patients at the time of tracheotomy was 15.8 months, ranging from 24 days to 17 years (Figure 1). Seventy three (48\%)of the patients were under one year of age at the time of tracheotomy. In 2011, the number of tracheotomies in our hospital increased significantly with the opening of the pediatric otolaryngology department and the expansion of the intensive care unit (Figure 2). The average lengths of hospital stay of patients before and after tracheostomy were 13 and 27 days, respectively.

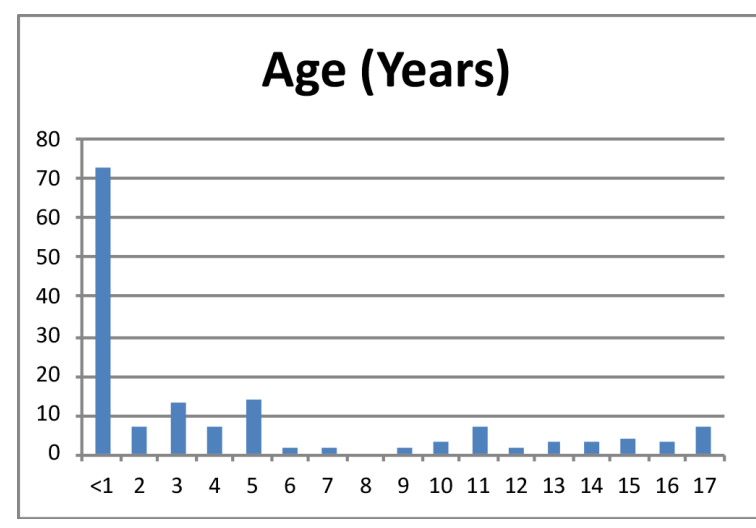

Figure 1: Age distribution of the patients.

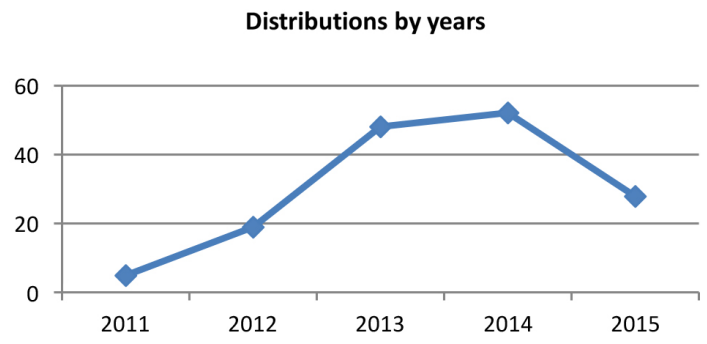

Figure 2: Patient' distributions by years. 


\subsection{Indications and preoperative evaluation}

All patients scheduled for tracheotomy were evaluated comprehensively. The details of the procedure were explained to parents and informed consent was obtained. In all cases, laboratory studies including complete blood count and coagulation parameters were performed (other tests were performed on a case-by-case basis depending on the underlying disease). All patients' airways were evaluated in detail before the procedure (from nasal passages to tracheal carina). Patients were classified as having neurological diseases (91 patients, 59.7\%), cardiopulmonary diseases (38 patients, 25\%), craniofacial abnormalities (14 patients, $9.2 \%$ ), airway obstruction (7 patients, $4 \%$ ) and trauma (2 patients, $1.3 \%$ ), according to etiology ${ }^{[5]}$. Details of etiologies are summarized in Tables I and II. All patients except 14 were followed up in the intensive care unit with intubation during the preoperative period. All patients except seven (96\%) were admitted to the emergency department with respiratory distress and general condition disturbance. Ninety-seven out of 152 (64\%) patients had pneumonia at the time of hospital admission. Distribution of pneumonia frequency according to etiology is summarized in Table II. In addition to tracheotomy, airway patency was provided by other surgical methods in eight patients with respiratory distress. Four cerebral palsy (CP) patients with respiratory distress underwent supraglottoplasty by diode laser. In a patient with Pierre-Robin syndrome, airway patency was provided by performing tongue-lip adhesion. In one patient, a vallecular cyst was detected and excised by diode laser. In one choanal atresia patient, a neo-choana was formed by transnasal endoscopic approach. Finally, one patient with mucopolysaccharidosis underwent adenotonsillectomy.

\subsection{Surgical technique}

All tracheotomies were performed by the same surgeons, FAA and NS. All cases were conducted under general anesthesia and in the supine position with shoulder rolls, if it was not contraindicated or an emergency situation. The head was hyper-extended in order to make the landmarks (cricoid cartilage, thyroid cartilage, hyoid bone and sternal notch) more apparent. A vertical skin incision was made in children less than one year of age, during an emergency and when the procedure was performed without assistance; in older children, a horizontal skin incision was preferred for cosmetic advantages. Subcutaneous tissues and strap muscles were dissected bluntly. Vertical tracheal incision was
Table 1: Patient Data Summary by Indications, complications and mortality.

\begin{tabular}{lc}
\hline Primary disease & $91(59,9 \%)$ \\
Neurological & $38(25 \%)$ \\
Cardiopulmonary & $14(9,2 \%)$ \\
Craniofacial & $7(4,6 \%)$ \\
Airway obstruction & $2(1,3 \%)$ \\
Trauma & $11(7.2 \%)$ \\
\hline Complication & 8 \\
Early & 1 \\
Accidental decannulation & 1 \\
Wound infection & 1 \\
Hemorrhage & $15(9,8 \%)$ \\
Cuff problem & 9 \\
& 1 \\
Late & 1 \\
Peristomal granulation & 2 \\
Mucus plug & 2 \\
Accidental decannulation & $26(17 \%)$ \\
Subglottic stenosis & $3(2 \%)$ \\
TIF* & 1 \\
Total & 1 \\
\hline Mortality related trach & 1 \\
Early decannulation & $9(5,9 \%)$ \\
Late decannulation & $12(7,8 \%)$ \\
TIF & \\
Mortality related disease progression & \\
Total & \\
\hline Tracheoinominate atery fistua & \\
\hline
\end{tabular}

*: Tracheoinominate artery fistula.

made in all cases. Before May 2014, stay suture was used alone in 91 (59.8\%) cases with 4-0 vicryl. Afterwards, maturation suture was used for $61(40.2 \%)$ tracheotomy cases with 4-0 vicryl. We secured the tracheotomy tube in place with soft tracheotomy ties (Velcro band)and skin sutures.

\subsection{Postoperative care}

Airway safety was provided by the surgical team or anesthesia team during transport from the operating room to the bed for all tracheotomy patients after the procedure. The service crew who cared for the patient was informed about the details of the procedure, and humidification and suction protocols were determined for each patient. The intubation set, the spare tracheotomy tube and the existing tube obturator were available at the bedside of the patient until the first tube change (postop first week), especially in patients with high risk of decannulation (short- and thicknecked patients such as those with mucopolysaccharidosis). In case of accidental decannulation, the approach (recannulation or intubation) to be performed was previously determined. 
Table 2: Categorized Indications for Tracheotomy and Deccannulation-Pneumonia rates.

\begin{tabular}{|c|c|c|c|}
\hline $\begin{array}{l}\text { Category } \\
\text { (n:152) }\end{array}$ & Diagnosis & $\begin{array}{c}\text { Decannulation rate \% } \\
\text { ( } \mathrm{n}: 20)\end{array}$ & $\begin{array}{c}\text { Pneumonia rates \% } \\
\text { (n:97) }\end{array}$ \\
\hline $\begin{array}{l}\text { Neurological } \\
\text { (n: 91) }\end{array}$ & $\begin{array}{l}\text { CP + MMR* } \\
\text { Intracranial tumors } \\
\text { Hypotonic infant } \\
\text { Hydrocephalus } \\
\text { SMA type } 1 * * \\
\text { SSPE*** } \\
\text { Birth asphyxia } \\
\text { Griscelli synd. } \\
\text { Status epilepticus } \\
\text { Traumatic brain injury }\end{array}$ & $\begin{array}{l}75 \% \\
(\mathrm{n}: 15)\end{array}$ & $\begin{array}{l}60,8 \% \\
(\mathrm{n}: 59)\end{array}$ \\
\hline $\begin{array}{l}\text { Cardiopulmonary } \\
\text { (n: } 38)\end{array}$ & $\begin{array}{l}\text { Pulmonary hypertension } \\
\text { Complete AVSD****} \\
\text { Aberrant subclavian artery } \\
\text { Acute respiretuar distres } \\
\text { Great vessel transposition } \\
\text { Congenital heart failure } \\
\text { Bronchopulmonary dysplasia }\end{array}$ & $\begin{array}{l}5 \% \\
(\mathrm{n}: 1)\end{array}$ & $\begin{array}{l}35,1 \% \\
(\mathrm{n}: 34)\end{array}$ \\
\hline $\begin{array}{l}\text { Craniofacial } \\
\text { (n: 14) } \\
\text { Crouzon syndrome } \\
\text { Zellweger syndrome } \\
\text { Mucopolysaccharidosis } \\
\text { Unspecified syndromic bak } \\
\text { Pierre Robin syndrome }\end{array}$ & & $\begin{array}{l}20 \% \\
(n: 4)\end{array}$ & $\begin{array}{l}4,1 \% \\
(n: 4)\end{array}$ \\
\hline $\begin{array}{l}\text { Upper airway obstruction } \\
\text { (n: 7) }\end{array}$ & $\begin{array}{l}\text { Subglottic hemangioma } \\
\text { Mandibular osteosarcoma } \\
\text { Vocal cord paralysis }\end{array}$ & 0 & 0 \\
\hline $\begin{array}{l}\text { Trauma } \\
(\mathrm{n}: 2)\end{array}$ & Maxillofacial trauma & 0 & 0 \\
\hline
\end{tabular}

\subsection{Complications}

\subsubsection{Early}

All complications in the first week of hospitalization were classified as early complications. Early complications were observed in $7.2 \%$ (11) of patients (Table 1). In one patient, the cuff was cut during tube insertion and the tube was changed in the operation room. In another patient, wound infection was observed on the fourth day. In a third patient, peristomal hemorrhage was observed on postoperative day three and hemostasis was achieved with cauterization. Accidental decannulation was observed in eight patients, and five of these were opened before the use of the maturation suture. Three of those patients were intubated by the service team and subsequently recannulated in the operating room by the primary surgeon. In one patient, massive sub- cutaneous emphysema was observed at the eighth post-operative hour, and it was seen that the tube came out of the trachea and entered a false passage. After recannulation, bilateral pneumothorax developed and a bilateral thoracic tube was placed. After one week, the pneumothorax resorbed and the tubes were removed. One patient died after accidental decannulation on the sixth post-operative day due to recannulation failure; after this death all tracheotomies were performed with maturation suture. In three patients who were operated on using the maturation suture, recannulation was performed in their service conditions without any complication.

\subsubsection{Late}

Late complications were observed in $9.8 \%$ (15) of patients 
(Table I). Bleeding from suprastomal granulation was observed in nine cases resulting in the granulation tissues being removed in the operating room. In one case, there was respiratory distress due to mucus plug in the second post-operative week; the plug was removed with flexible bronchoscopy. In two cases stage 4 subglottic stenosis was observed. Airway patency was provided by repeated surgical intervention with diode laser and both patients were decannulated. One patient who underwent tracheotomy due to subglottic hemangiomas died after accidental decannulation in the first postoperative year. The decannulation occurred at the patient's home, and the patient had respiratory fatigue and carbon dioxide retention when admitted to the hospital. Respiratory arrest was observed at the first evaluation in emergency room. The stoma had completely closed spontaneously and recannulation attempts failed. Although the patient was intubated eventually, many unsuccessful intubations were attempted. Irreversible brain damage occurred due to prolonged hypoxia and the patient died after one week. One patient died due to unidentified abundant hemorrhage from trachea at the sixth post-operative month and this event was considered to be a possible tracheoinnominate artery fistula (TIF). In another case, abundant hemorrhage was observed from the trachea at the third post-operative month and stopped spontaneously a few minutes later. When we examined the trachea with a flexible fiberoptic endoscope, granulation tissue was observed on the anterior wall of the trachea, consistent with innominate artery localization. Additionally, in contrast-enhanced computed tomography, the artery was seen very close to the tracheal wall. The patient was accepted as having a TIF, and immediately a self-expandable stent was placed into the innominate artery by an interventional radiologist. The bleeding did not recur after the intervention.

\subsection{Decannulation outcomes}

None of the 152 patients who had undergone tracheotomy could be decannulated during the hospitalization period. Nine of 152 (6\%) patients died from primary disease progression without being discharged. One hundred twelve (78\%) of the remaining 143 patients needed mechanical ventilator support during discharge. Three out of $31 \mathrm{pa}-$ tients who tolerated self ventilation died of tracheotomy-related causes before decannulation. Twenty out of the remaining 28 cases (13\%) were successfully decannulated, while eight were not. Decannulation rate was highest in patients with craniofacial abnormalities (28.5\%), whereas no patients in the upper airway obstruction and trauma groups were decannulated. Flexible laryngobroncoscopy was performed under sedation anesthesia in all patients before decannulation. Patients without airway obstruction were decannulated and followed up for at least 24 hours. In two patients stage 4 subglottic stenosis was observed and airway patency was provided by repeated surgical intervention with diode laser, which resulted in successful decannulation (mentioned above in section 3.5.2). Despite the lack of obstruction in the airway, decannulation was not achieved in the remaining eight patients. Decannulation outcomes are summarized in Table II.

\section{Discussion}

There have been many changes in pediatric tracheotomy practice over the past 40 years. Namely, there has been a dramatic shift in tracheotomy indications from acute upper respiratory tract obstruction due to infections to diseases leading to prolonged mechanical ventilator support. This shift has also affected postoperative care and follow-up results. Campisi et al. evaluated the indications of pediatric tracheotomy cases between 1963 and $2009{ }^{[10]}$. According to this study, between 1963-70, infections were the most common indication, with a rate of $49 \%$; in the 1980 s, concurrent with a rise in vaccinations, this indication decreased to $14 \%$, and then decreased to $3 \%$ after the start of the 2000 s, when airway abnormalities (58\%) and neurological deficits $(31 \%)$ became the most common indications for tracheotomies. In another study, when 37-year outcomes were examined, the most common indication between 1960 and 1980 was acute upper respiratory tract obstruction caused by infection. After the 1980s diseases leading to prolonged mechanical ventilator support became the most common indications ${ }^{[6]}$; similar results were also observed in other studies ${ }^{[1,12,13]}$. In our study, which was comprised of 152 tracheotomy cases performed between 2011-2015, neurological and cardiopulmonary diseases were the most common indications, with rates of $59.9 \%$ and $25 \%$, respectively.

The aforementioned studies and our own have both shown that, in the coming years, diseases leading to prolonged intubation will be the most common pediatric tracheotomy indications. The most prominent of these are neurological diseases, particularly birth asphyxia, central nervous system infections, trauma, stroke, genetic disorders, intracranial tumors and those secondary to other syndromic diseases ${ }^{[14]}$. A considerable number of these patients have 
severe airway obstruction due to decreased neuromuscular tonus [15].

Continuous or biphasic positive airway pressure (CPAP and BIPAP, respectively) and adenotonsillectomy are the most common approaches to provide airway patency, though many surgical procedures have been used for this purpose ${ }^{[16-18]}$. However, the severity of these problems increases with age, and tracheotomy is often the option of last resort ${ }^{[19]}$. In our study, airway patency was achieved without tracheotomy in eight patients by using a different surgical procedure.In patients with neurological diseases, another important problem is increased oropharyngeal aspiration (OPA) due to impaired swallowing function ${ }^{[14]}$. While many OPA cases are manifested with cough, OPA sometimes remains silent due to decreased cough reflex, especially in those with neurological disease. Weir et al. assessed 300 pediatric cases with swallowing difficulty in their study and showed that $81 \%$ of patients with OPA had silent aspiration, while also noting that silent aspiration is more common in neurological impairment and developmental delay ${ }^{[20]}$. In another study conducted by Weir et al., increased OPA in patients with neurological deficits was shown to increase the risk of recurrent pneumonia ${ }^{[21]}$.

Children with neurological deficits are more susceptible to pneumonia attacks and serious complications, and death due to respiratory failure is more common in this group ${ }^{[22-24]}$. In addition, the incidence of complications and mortality due to influenza and respiratory syncytial virus (RSV) infection is higher in these patients ${ }^{[25,26]}$. Respiratory failure after recurrent pneumonia in these children is the most important cause of mechanical ventilation dependence ${ }^{[27]}$. In our study, $63.8 \%$ (97) of cases were admitted to the intensive care unit due to pneumonia (Table II). These patients came to the emergency service with acute respiratory distress and were subsequently transported to the PICU. All of these patients were intubated after admission to the PICU and none were able to tolerate extubation. Of the patients who were admitted due to pneumonia, 59 had neurological deficits, 34 had cardiopulmonary disease and 4 had craniofacial abnormalities. As noted previously, these patient groups are more susceptible to aspiration-induced pneumonia and infections such as influenza and RSV.

Despite recent medical developments, complications that may result in mortality in pediatric tracheotomy cases continue to be seen, with complication rates in the literature ranging from 11 to $51 \%{ }^{[6,7,28]}$. Early complications (within the first week of hospitalization) include bleeding, infection, pneumothorax, tube obstruction and accidental decannulation. Late complications include airway stenosis, failure of decannulation or development of suprastomal granulation, which can lead to respiratory failure and airway obstruction after decannulation. Less common late complications include tracheomalacia, tracheoinominate artery fistula (TIF), tracheoesophageal fistula (TEF), pneumonia and aspiration, each of which may be associated with significant morbidity and mortality ${ }^{[29]}$. In our study, we encountered early complications in 11 cases $(7.2 \%)$ and late complications in 15 cases $(9.8 \%)$. The most common complication was peristomal granulation tissue. In two cases TIF was observed, and one of these patients died due to TIF (Table I). Major complications such as TIF are known to occur more frequently in pediatric tracheotomy patients ${ }^{[30]}$. Diseases that cause displacement of intrathoracic structures such as kyphoscoliosis are more common in pediatric tracheotomy cases and the fact that both the trachea and the arterial walls are weaker explain why this complication is common in these groups. There was severe kyphoscoliosis in both our TIF cases due to CP.

Due to the functional, psychological and financial burden of long-term tracheotomy care, decannulation has always been the ultimate goal. In US, the annual cost of a tracheostomy patient is approximately $\$ 110,000$, of which about $60 \%$ is nursing costs ${ }^{[31]}$. Decannulation rates in the literature range from 35 to $75 \%{ }^{[8,11,32-35]}$. The most important reason for this wide range is the diverse profile of patients who have tracheotomy. Funamura et al. showed that the decannulation rate was higher in patients with tracheotomy due to trauma than in patients with tracheotomy due to cardiopulmonary and neurological diseases ${ }^{[5]}$. We were able to decannulate $13 \%$ (20) of cases. The primary reason why our decannulation rate is low is that the vast majority of our patients $(73.6 \%)$ needed mechanical ventilation during follow-up due to the nature of the primary diseases. The other reason is that our hospital is not a trauma center, so the emergency department only accepts patients in extraordinary situations, usually those involving severe trauma. Unfortunately, we could not decanulate any of our trauma patients due to severe brain damage. However, the literature supports increased decanulation rates of trauma patients, which is contrary to the results of our study. We believe the difference is related to the severity of trauma. Although we performed the tracheotomy with a surgical approach in all cases, in the coming years percutaneous tracheotomy may be more commonly used. Percutaneous tracheotomy (PT) has long been a safe and feasible procedure in adult ICU patients. PT is generally considered 
to be contraindicated in children, especially in infants less than one year of age, because their tracheas are relatively small, mobile and foldable ${ }^{[3]}$. Studies and case reports regarding the use of PT in children exist but the number of cases is fairly limited ${ }^{[37-39]}$. One of the largest such studies in the literature was published by Göllü et al. with 51 cases ${ }^{[40]}$. In this study, $92 \%$ of the cases were under 10 years-old and $43 \%$ were under one year-old. Only one major complication (tracheal posterior and esophageal anterior wall perforation) was observed in one out of 51 cases. In order for PT to be accepted at more centers, there is a need for studies with a higher number of cases and long-term follow-up results.

\section{References}

[1] Fraga JC, De Souza JCK, Kruel J. Pediatric tracheostomy. J Pediatr (Rio J) 2009;85:97-103.

[3] Olszewski J, Miłoǹski J. History of tracheotomy. Otolaryngol Pol 2007;61:349-52.

[4] Cummings, C.W., Flint P, Haugley B, Lund V, Niparko J, Robbins K, Regan T, Lesperance M. (2015). Cummings Otolaryngology:Head and neck surgery. (pp. 95-103) Philedelphia:Elsevier/Saunders.

[6] Carron JD, Derkay CS, Strope G, Nosonchuk JE, Darrow DH. Pediatric tracheotomies: changing indications and outcomes. Laryngoscope 2000;110:1099-104.

[7] Funamura JL, Durbin-Johnson B, Tollefson TT, Harrison J, Senders CW. Pediatric tracheotomy: Indications and decannulation outcomes. Laryngoscope. 2014;124:1952-8.

[8] Lewis CW, Carron JD, Perkins JA, Sie KC, Feudtner C. Tracheotomy in pediatric patients: a national perspective. Arch Otolaryngol Head Neck Surg 2003;129:523-9.

[9] Jaryszak EM, Shah RK, Amling J, Peña MT. Pediatric tracheotomy wound complications: incidence and significance. Arch Otolaryngol Head Neck Surg 2011;137:363-6.

[10] Ozmen S, Ozmen OA, Unal OF. Pediatric tracheotomies: a 37year experience in 282 children. Int J Pediatr Otorhinolaryngol 2009;73:959-61.

[11] Zenk J, Fyrmpas G, Zimmermann T, Koch M, Constantinidis J, Iro H. Tracheostomy in young patients: indications and long-term outcome. Eur Arch Otorhinolaryngol 2009;266:705-11.

[12] Campisi P, Forte V. Pediatric tracheostomy. Seminars in Pediatric Surgery 2016;25:191-5.

[13] Mahadevan M, Barber C, Salkeld L, Douglas G, Mills N. Pediatric tracheotomy: 17-year review. Int J Pediatr Otorhinolaryngol 2007;71:1829-35.

[14] Kremer B, Botos-Kremer AI, Eckel HE, Schlondorff G. Indica-

\section{Conclusion}

The most common tracheotomy indications in recent years are diseases that lead to mechanical ventilator support, such as neurological and cardiopulmonary diseases. Consequently, these situations reduce decannulation rates and increase the need for chronic care. One of the most important aims in the management of patients with tracheotomy should be the prevention of mechanical ventilation dependence, which increases the risk of respiratory failure.

Acknowlements: All authors thank to Quinton Mandle for his English reductions. tions, complications, and surgical techniques for pediatric tracheostomies—an update. J Pediatr Surg 2002;37:1556-62.

[15] Ang AH, Chua DY, Pang KP, Tan HK. Pediatric tracheotomies in an Asian population: The Singapore experience. Otolaryngol Head Neck Surg 2005;133:246-50.

[16] Erasmus CE, van Hulst K, Rotteveel JJ, Willemsen MA, Jongerius PH. Clinical practice: swallowing problems in cerebral palsy. Eur J Pediatr 2012;171:409-14.

[17] Wilkinson DJ, Baikie G, Berkowitz RG, Reddihough DS. Awake upper airway obstruction in children with spastic quadriplegic cerebral palsy. J Paediatr. Child Health 2006;42:44-8.

[18] Magardino TM, Tom LW. Surgical management of obstructive sleep apnea in children with cerebral palsy. Laryngoscope 1999;109:1611-5.

[19] Kosko JR, Derkay CS. Uvulopalatopharyngoplasty: treatment of obstructive sleep apnea in neurologically impaired pediatric patients. Int J Pediatr Otorhinolaryngol 1995;32:241-6.

[20] Cohen SR, Simms C, Burstein FD, Thomsen J. Alternatives to tracheostomy in infants and children with obstructive sleep apnea. J Pediatr Surg 1999;34:182-6.

[21] Kontorinis G, Thevasagayam MS, Bateman ND. Airway obstruction in children with cerebral palsy: Need for tracheostomy? Int J Pediatr Otorhinolaryngol 2013;77:1647-50.

[22] Weir KA, McMahon S, Taylor S, Chang AB. Oropharyngeal aspiration and silent aspiration in children. Chest 2011;140:589-97.

[23] Weir K, McMahon S, Barry L, Ware R, Masters IB, Chang AB. Oropharyngeal aspiration and pneumonia in children. Pediatr Pulmonol 2007;42:1024-31.

[24] Healy FM, Panitch HB. Pulmonary complications of pediatric neurological diseases. Pediatr Ann 2010;39:216-24.

[25] Dodge NN. Cerebral palsy: medical aspects. Pediatr Clin North Am 2008;55: 1189-207 
[26] Seddon PC, Khan Y. Respiratory problems in children with neurological impairment. Arch Dis Child 2003;88:75-8.

[27] Wilkesmann A, Ammann RA, Schildgen O, Eis-Hubinger AM, Muller A, Seidenberg J, et al. Hospitalized children with respiratory syncytial virüs infection and neuromuscular impairment face an increased risk of a complicated course. Pediatr Infect Dis J 2007;26:485-91.

[28] Blanton L, Peacock G, Cox C, Jhung M, Finelli L, Moore C. Neurologic disorders among pediatric deaths associated with the 2009 pandemic influenza. Pediatrics 2012;130:390-6.

[29] Millman AJ, Finelli L, Bramley AM, Peacock G, Williams DJ, Arnold SR, et al. Community-Acquired Pneumonia Hospitalization among Children with Neurologic Disorders. J Pediatr 2016;173:188-95.

[30] Carr MM, Poje CP, Kingston L, Kielma D, Heard C. Complications in pediatric tracheostomies. Laryngoscope 2001;111:1925-8.

[31] Epstein SK. Late complications of tracheostomy. Respir Care 2005;50:542-9.

[32] Das P, Zhu H, Shah RK, Roberson DW, Berry J, Skinner ML. Tracheotomy-Related Catastrophic Events: Results of a National Survey. Laryngoscope 2012;122:30-7.

[33] Fields AI, Rosenblatt A, Pollac MM, et al. Home care cost-effectiveness for respiratory technology-dependent children. Am J Dis Child 1991;145:729-33.
[34] French LC, Wootten CT, Thomas RG, Neblett WW, Werkhaven JA, Cofer SA. Tracheotomy in the preschool population: indication and outcomes. Otolaryngol Head Neck Surg 2007;137:280-3.

[35] de Trey L, Niedermann E, Ghelfi D, Gerber A, Gysin C. Pediatric tracheotomy: a 30-year experience. J Pediatr Surg 2013;48:1470-5.

[36] Tantinikorn W, Alper CM, Bluestone CD, Casselbrant ML. Outcome in pediatric tracheotomy. Am J Otolaryngol 2003;24:131-7.

[37] Leung R, Berkowitz RG. Decannulation and outcome following pediatric tracheostomy. Ann Otol Rhinol Laryngol 2005;114:7438.

[38] Kost KM, Endoscopic percutaneous dilatational tracheotomy: a prospective evaluation of 500 consecutive cases. Laryngoscope 2005;115:1-30.

[39] Scott CJ, Darowski M, Crabbe DC. Complications of percutaneous dilatational tracheostomy in children. Anaesthesia 1998;53:477-80.

[40] Zawadzka-Glos L, Rawicz M, Chmielik M. Percutaneous tracheotomy in children. Int J Pediatr Otorhinolaryngol 2004;68:1387-90.

[41] Toursarkissian B, Fowler CL, Zweng TN, et al. Percutaneous dilational tracheostomy in children and teenagers. J Pediatr Surg 1994;29:1421-4.

[42] Gollu G, Ates U, Can OS, Kendirli T, Yagmurlu A, Cakmak M, et al. Percutaneous tracheotomy by Griggs technique under rigid bronchoscopic guidance is safe and feasible in children. J Pediatr Surg 2016;51:1635-9.

This is an open access article distributed under the terms of the Creative Commons Attribution-NonCommercial-NoDerivs 3.0 Unported (CC BYNC-ND3.0) Licence (http://creativecommons.org/licenses/by-nc-nd/3.0/) which permits unrestricted noncommercial use, distribution, and reproduction in any medium, provided the original work is properly cited.

Please cite this article as: Alper Akcan F, Dündar Y, Uluat A, Cebeci D, Sungur M. A, Salman N, Ünlü İ,. Pediatric tracheotomies: A 5-year experience in 152 children. ENT Updates 2018;8(2): 71-78. 